\title{
Tocotrienols-induced inhibition of platelet thrombus formation and platelet aggregation in stenosed canine coronary arteries
}

Asaf A Qureshi ${ }^{1,2^{*}}$, Charles W Karpen ${ }^{3}$, Nilofer Qureshi ${ }^{1,4}$, Christopher J Papasian ${ }^{1}$, David C Morrison ${ }^{1}$ and John D Folts ${ }^{5}$

\begin{abstract}
Background: Dietary supplementation with tocotrienols has been shown to decrease the risk of coronary artery disease. Tocotrienols are plant-derived forms of vitamin E, which have potent anti-inflammatory, antioxidant, anticancer, hypocholesterolemic, and neuroprotective properties. Our objective in this study was to determine the extent to which tocotrienols inhibit platelet aggregation and reduce coronary thrombosis, a major risk factor for stroke in humans. The present study was carried out to determine the comparative effects of $\alpha$-tocopherol, $\alpha$-tocotrienol, or tocotrienol rich fraction (TRF; a mixture of $\alpha-+\gamma^{-}+$ $\delta$-tocotrienols) on in vivo platelet thrombosis and ex vivo platelet aggregation (PA) after intravenous injection in anesthetized dogs, by using a mechanically stenosed circumflex coronary artery model (Folts' cyclic flow model).

Results: Collagen-induced platelet aggregation (PA) in platelet rich plasma (PRP) was decreased markedly after treatment with $\boldsymbol{\alpha}$-tocotrienol (59\%; $\boldsymbol{P}<0.001)$ and TRF (92\%; $\boldsymbol{P}<0.001)$. $\boldsymbol{\alpha}$-Tocopherol treatment was less effective, producing only a 22\% $(\boldsymbol{P}<0.05)$ decrease in PA. Adenosine diphosphate-induced (ADP) PA was also decreased after treatment with $\boldsymbol{\alpha}$-tocotrienol (34\%; $\boldsymbol{P}<0.05)$ and TRF (42\%; $\boldsymbol{P}<0.025)$. These results also indicate that intravenously administered tocotrienols were significantly better than tocopherols in inhibiting cyclic flow reductions (CFRs), a measure of the acute platelet-mediated thrombus formation. Tocotrienols (TRF) given intravenously (10 mg/kg), abolished CFRs after a mean of $68 \mathrm{~min}$ (range $22-130 \mathrm{~min}$ ), and this abolition of CFRs was sustained throughout the monitoring period (50 - $160 \mathrm{~min}$ ).

Next, pharmacokinetic studies were carried out and tocol levels in canine plasma and platelets were measured. As expected, $\alpha$-Tocopherol treatment increased levels of total tocopherols in post- vs pre-treatment specimens (57 vs $18 \mu \mathrm{g} / \mathrm{mL}$ in plasma, and 42 vs $10 \mu \mathrm{g} / \mathrm{mL}$ in platelets). However, treatment with $\alpha$-tocopherol resulted in slightly decreased levels of tocotrienols in post- vs pre-treatment samples (1.4 vs $2.9 \mu \mathrm{g} / \mathrm{mL}$ in plasma and 2.3 vs $2.8 \mathrm{\mu g} / \mathrm{mL}$ in platelets). $\alpha$-Tocotrienol treatment increased levels of both tocopherols and tocotrienols in post- vs pre-treatment samples (tocopherols, $45 \mathrm{vs} 10 \mu \mathrm{g} / \mathrm{mL}$ in plasma and $28 \mathrm{vs} 5 \mu \mathrm{g} / \mathrm{mL}$ in platelets; tocotrienols, $2.8 \mathrm{vs} 0.9 \mu \mathrm{g} / \mathrm{mL}$ in plasma and $1.28 \mathrm{vs} 1.02 \mu \mathrm{g} / \mathrm{mL}$ in platelets). Treatment with tocotrienols (TRF) also increased levels of tocopherols and tocotrienols in post- vs pre-treatment samples (tocopherols, 68 vs 20 $\mu \mathrm{g} / \mathrm{mL}$ in plasma and $31.4 \mathrm{vs} 7.9 \mu \mathrm{g} / \mathrm{mL}$ in platelets; tocotrienols, $8.6 \mathrm{vs} 1.7 \mu \mathrm{g} / \mathrm{mL}$ in plasma and $3.8 \mathrm{vs} 3.9 \mu \mathrm{g} /$ $\mathrm{mL}$ in platelets).
\end{abstract}

Conclusions: The present results indicate that intravenously administered tocotrienols inhibited acute plateletmediated thrombus formation, and collagen and ADP-induced platelet aggregation. $\boldsymbol{\alpha}$-Tocotrienols treatment induced increases in $\alpha$-tocopherol levels of 4 -fold and 6-fold in plasma and platelets, respectively. Interestingly, tocotrienols (TRF) treatment induced a less pronounced increase in the levels of tocotrienols in plasma and

\footnotetext{
* Correspondence: qureshia@umkc.edu

'Department of Basic Medical Science, School of Medicine, 2411 Holmes

Street, University of Missouri, Kansas City. MO 64108, USA

Full list of author information is available at the end of the article
} 
platelets, suggesting that intravenously administered tocotrienols may be converted to tocopherols. Tocotrienols, given intravenously, could potentially prevent pathological platelet thrombus formation and thus provide a therapeutic benefit in conditions such as stroke and myocardial infarction.

\section{Background}

Americans are often encouraged to consume more fruits and vegetables, and eat less red meat and dairy products, in order to lower total and LDL-cholesterol levels and reduce the risk of developing atherosclerosis, platelet mediated coronary thrombosis, myocardial infarctions, and strokes $[1,2]$. It is now known that oxidized LDL-cholesterol is a much greater risk factor for the development of atherosclerosis than its non-oxidized precursor [3-7]. Dietary antioxidants, such as vitamin E ( $\alpha$-tocopherol), have been shown to prevent LDL oxidation and limit hypercholesterolemia in humans $[8,9]$, and it has been proposed that Vitamin E can prevent vascular thrombosis and atherosclerosis [8-11]. A number of studies have suggested that dietary intake of small doses of $\alpha$-tocopherol reduces the risk of developing coronary atherosclerosis $[9,10]$, although this has not been a universal finding $[12,13]$.

The inhibitory effects of $\alpha$-tocopherol on platelet function in vivo and ex vivo have been well established [14-18], but inhibition of platelet aggregation by $\alpha$-tocopherol in vitro requires non-physiologically high levels of $\alpha$-tocopherol [14]. It is not surprising, therefore, that the results of in vivo and in vitro studies are often in conflict when studying the effects of $\alpha$-tocopherol on platelet aggregation [14-18]. The mechanism by which $\alpha$-tocopherol reduces thrombosis and atherosclerosis is not well defined $[7,8]$, though a number of possible mechanisms have been proposed; the antioxidant properties of $\alpha$-tocopherol are often implicated [8]. Recently, several investigators have reported that tocotrienols (unsaturated vitamin E) have 10- to 20 -fold greater antioxidant activity than $\alpha$-tocopherol (vitamin E), and provide more efficient protection against certain free radical-related diseases than $\alpha$-tocopherol [19-28].

The positive effects of tocotrienols (unsaturated vitamin E; Figure 1) as anti-inflammatory, antioxidant, anticancer (anti-proliferative), hypocholesterolemic, and neuroprotective agents in animal and humans have been confirmed by several investigators [23,29-39]. Tocotrienols are naturally-occurring farnesylated unsaturated analogs of $\alpha-, \beta-, \gamma$ - and $\delta$-tocopherols (Figure 1 ) isolated from barley, rice bran, and annatto seeds [21]. The Folts' arterial injury model of stenosis and thrombosis provides a system for evaluating the effects of various natural products in vivo and ex vivo on platelet aggregation and thrombus formation [40]. In the experiments described in this manuscript, we determined the effects of $\alpha$-tocopherol, $\alpha$-tocotrienol, and a purified tocotrienol rich fraction from palm oil without $\alpha$-tocopherol (TRF) on both in vivo platelet thrombus formation and ex vivo platelet aggregation in the Folts' model using anesthetized dogs with mechanically stenosed circumflex coronary arteries (MSCCA). The concentrations of tocopherols and tocotrienols were also estimated in pre-dose and post-dose samples of plasma and platelets.

\section{Materials and methods Materials}

Soluble equine tendon type I collagen and adenosine diphosphate (ADP) were purchased from Chrono-Log Corp (Havertown, PA, USA). Manual platelet counting was performed using the Unipette System. Dogs were obtained from the Medical School Facility of the University of Wisconsin, Madison, 53706, USA.

The investigation conforms with the guidelines for the care and use of laboratory animals by the US National Institute of Health (NIH publication 85-23, revised 1996), and the University of Wisconsin Research Animal Resource Center. The protocol was reviewed and approved by the University of Wisconsin-Madison College of Agricultural and Life Sciences Animal Care and Use Committee.

\section{Canine model and surgical preparation}

Ten dogs were anesthetized, the chest opened and the heart exposed. The left circumflex coronary artery was dissected out and an electromagnetic flow probe placed circumferentially as previously described [40]. Distal to the flow probe, the artery was clamped three times with a special surgical clamp to produce intimal and medial damage, and a plastic cylinder of appropriate diameter was then placed circumferentially to produce a $70 \%$ reduction in internal arterial diameter [40]. Plateletmediated thrombi periodically form at the site of stenosis, and embolize distally. These thrombi were monitored by the flow probe as cyclic flow reductions (CFRs) in coronary blood flow (40). The size and frequency of these CFRs is directly related to the level of in vivo platelet activity [40]. The average body weight of the dogs was $25 \pm 0.6 \mathrm{~kg}$ for all groups.

\section{Preparation of TRF (mixture of $\alpha-+\gamma-\delta$-tocotrienols) free of $\alpha$-tocopherol from palm oil by flash chromatography}

Silica gel (Merck, 230-400 mesh, $60 \AA$ A, 500 g) suspended in $1000 \mathrm{~mL}$ of hexane was poured into a $1-\mathrm{L}$ glass 


\section{Analogs of Tocotrienols}<smiles>[R2]c1c([R2])c2c(c([R])c1O)O[C@]([Z6])(CC/C=C(\C)CC/C=C(\C)CCC=C(C)C)CC2</smiles>

$\alpha$-T3, $\alpha$-Tocotrienol $\beta$-T3, $\beta$-Tocotrienol $\gamma$-T3, $\gamma$-Tocotrienol $\delta$-T3, $\delta$-Tocotrienol

\section{$\begin{array}{llll}R_{1} & R_{2} & R_{3} & R_{4}\end{array}$}

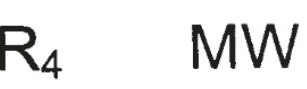


reported previously [40]. The TRF used throughout present study is a mixture of $\alpha-, \gamma-$, and $\delta$-tocotrienols, free of $\alpha$-tocopherol.

\section{Ex vivo platelet aggregation}

Canine platelet aggregation was performed using a modification of a previously described human platelet methodology $[18,40]$. Blood $(30 \mathrm{~mL})$ was drawn through a femoral arterial line into $3.8 \%$ sodium citrate (1 citrate to 9 parts blood). Platelet-rich plasma (PRP) was isolated by centrifugation at $250 \times \mathrm{g}$ for $15 \mathrm{~min}$. Platelet-rich plasma was separated and platelet counting was performed. The remaining blood was centrifuged further at $2,000 \times \mathrm{g}$ for 20 minutes and platelet-free plasma (PFP) isolated. PRP platelet counts were adjusted with corresponding PFP to equalize counts between pre- and post-treatment specimens. PRP counts varied between 100,000 and 200,000 platelets/microliter. Platelet aggregation was performed using a Sienco DP 247-E Dual Sample Aggregometer (Morrison CO) and Omniscribe recorder (Houston Instruments Model A5211-1), adjusting PRP to $10 \%$ transmittance and PFP to $90 \%$ transmittance.

Collagen $(12.5 \mu \mathrm{mol} / \mathrm{mL})$ or ADP $(20 \mu \mathrm{mol} / \mathrm{L})$, in volumes of $32 \mu \mathrm{L}$ were added to PRP $(400 \mu \mathrm{L})$, after the PRP was incubated at $37^{\circ} \mathrm{C}$ for $2 \mathrm{~min}$. The extent of collagen-induced platelet aggregation was quantitated by measuring the percent aggregation $6 \mathrm{~min}$ after the addition of collagen. ADP-induced platelet aggregation was quantitated by measuring percent aggregation at both 2.5 and 6.0 min after adding ADP.

\section{Isolation and analyses of tocopherols and tocotrienols in plasma and platelets by HPLC}

Blood $(30 \mathrm{~mL})$ was drawn in EDTA (0.8 parts $77 \mu \mathrm{M}$ disodium EDTA to 9.2 parts blood) and PRP was prepared from pre-dose and post-dose specimens as described above. Platelets were separated from PRP by centrifugation at $1950 \times \mathrm{g}$ for $20 \mathrm{~min}$ and the platelet pellet washed twice with phosphate-buffered saline (PBS). The final platelet pellet was suspended in $1 \mathrm{~mL}$ PBS and platelets were counted. All samples were stored at $-20^{\circ} \mathrm{C}$ until assayed.

Estimations of tocols (mixture of $\alpha-, \beta-, \gamma-, \delta$-tocopherol $+\alpha-, \beta-, \gamma-, \delta$-tocotrienols) in plasma and platelet fractions were carried out by HPLC using a modification of a previously-described methodology [41]. Plasma (2 $\mathrm{mL})$ or platelets $(1 \mathrm{~mL})$ were added to a $20 \mathrm{~mL}$ culture tube, hexane $(6 \mathrm{~mL})$ was added, and these samples were shaken in a horizontal shaker for $20 \mathrm{~min}$, followed by centrifugation at $1000 \times \mathrm{g}$ for $10 \mathrm{~min}$. The hexane layer (free tocols) was transferred to a $15-\mathrm{mL}$ conical tube and the solvent was removed under vacuum at $50^{\circ} \mathrm{C}$ in a vortex evaporator. The remaining aqueous layer was dried at $120^{\circ} \mathrm{C}$ in a vacuum oven $(2 \mathrm{psi})$ for $60 \mathrm{~min}$. The residue was extracted with methanol $(6 \mathrm{~mL})$ using a horizontal shaker for $30 \mathrm{~min}$ and centrifuged at $1000 \times$ $\mathrm{g}$ for $15 \mathrm{~min}$. The methanol soluble fraction (bound tocols) was separated and concentrated under vacuum at $50^{\circ} \mathrm{C}$ in a vortex evaporator. Tocols extracted by each solvent were dissolved in hexane $(0.5 \mathrm{~mL})$, vortexed and transferred to injecting vials $(250 \mu \mathrm{L})$ the vials were capped and centrifuged at $1000 \times \mathrm{g}$ for $5 \mathrm{~min}$, followed by HPLC analyses [41]. The tocols were eluted under these conditions in sequence; $\alpha$-tocopherol (5.2 $\mathrm{min}$ ), $\alpha$-tocotrienol (5.6 $\mathrm{min}), \beta$-tocopherol $(6.8 \mathrm{~min})$, $\beta$-tocotrienol (7.2 $\mathrm{min}), \gamma$-tocopherol $(7.8 \mathrm{~min}) \gamma$-tocotrienol $(8.1 \mathrm{~min}), \delta$-tocopherol $(16.8 \mathrm{~min})$ and $\delta$-tocotrienol (18.4 $\mathrm{min})$, respectively. Values of the four separate isomers of $\alpha-, \beta-, \gamma$ - and $\delta$-tocopherols and tocotrienols were estimated separately, but combined values for the four isomers of tocopherols or tocotrienols were reported.

\section{Statistical analyses}

The data were analyzed by using the GLM procedure of SAS (Statistical Analysis System) for personal computers to test the Duncan's multiple-range test to determine whether the post-dose treated values differed from the pre-dose values for $\alpha$-tocopherol, $\alpha$-tocotrienol, or TRF treated groups. A two-way ANOVA was used to test whether changes in collagen or ADP treated platelet aggregation occurs during the treatments and whether there were intra or inter-group differences between tocol levels. The differences between means were also evaluated using the paired, two-tailed student $t$-test (StarView, Abacus Concept) and data were reported as mean \pm in the standard deviation. The level of statistical significance was reported at $5 \%(\boldsymbol{P}<0.05)$.

\section{Results}

Effects of tocols on the levels of hematocrit and number of platelets (counts) in whole blood and platelet rich plasma (PRP)

In order to obtain an initial assessment of the effects of treatment with various tocols on factors potentially effecting thrombosis in dogs, we first measured the effects of these treatments on hematocrit and platelet counts. There were no significant differences between pre-dose and post-dose hematocrit levels after treatment with $\alpha$-tocopherol $(47.97 \pm 6.36$ vs $48.33 \pm 0.64)$, $\alpha$-tocotrienol $(49.47 \pm 1.87$ vs $46.40 \pm 2.99)$, or TRF $(46.45 \pm 5.84$ vs $41.45 \pm 7.01)$ as shown in Table 1 . The cumulative average pre-dose and post-dose platelet counts in whole blood also did not change significantly after treatment with $\alpha$-tocopherol (234.83 \pm 42.09 vs $188.33 \pm 54.47)$, $\alpha$-tocotrienol $(262.67 \pm 49.61$ vs 188.00 $\pm 36.23)$, or TRF $(28.38 \pm 63.25$ vs $207.25 \pm 43.25)$. In 
Table 1 Effects of tocols on hematocrit levels, and the number of platelets in whole blood and in platelet rich plasma in stenosed canine arteries

\begin{tabular}{|c|c|c|}
\hline \multirow[b]{2}{*}{ Dogs } & \multicolumn{2}{|c|}{ Hematocrit $^{1}$} \\
\hline & Pre-dose & Post-dose \\
\hline$\overline{\alpha \text {-Tocopherol }}$ & $47.97 \% \pm 6.36(100)^{4}$ & $48.33 \% \pm 0.64(101)$ \\
\hline$\overline{\alpha \text {-Tocotrienol }}$ & $49.47 \% \pm 1.87(100)$ & $46.40 \% \pm 2.99(94)$ \\
\hline$\overline{\text { TRF }^{3}}$ & $46.45 \% \pm 5.84(100)$ & $41.45 \% \pm 7.01$ \\
\hline
\end{tabular}

\begin{tabular}{lll}
\hline & Platelet Counts in Whole Blood & \\
\hline Dogs & Pre-dose & Post-dose \\
\hline
\end{tabular}

\begin{tabular}{|c|c|c|}
\hline$\overline{\alpha \text {-Tocopherol }}$ & $234.83 \pm 42.09(100)^{4}$ & $188.33 \pm 54.47(80)$ \\
\hline$\overline{\alpha-T o c o t r i e n o l}$ & $262.67 \pm 49.61(100)$ & $188.00 \pm 36.23(72)$ \\
\hline$\overline{\mathrm{TRF}^{3}}$ & $280.38 \pm 63.25(100)$ & $207.25 \pm 43.25(74)$ \\
\hline
\end{tabular}

\begin{tabular}{lcc}
\hline & \multicolumn{1}{c}{ Platelet Counts in Platelet Rich Plasma ${ }^{1}$} \\
\hline Dogs & Pre-dose & Post-dose \\
\hline
\end{tabular}

$\begin{array}{lll}\alpha \text {-Tocopherol } & 196.00 \pm 6.93(100)^{4} & 194.22 \pm 6.00(99)\end{array}$

\begin{tabular}{lll}
$\overline{\alpha-\text { Tocotrienol }}$ & $187.67 \pm 10.79(100)$ & $175.33 \pm 10.79(93)$ \\
\hline & $170.00 \pm 24.49(100)$ & $164.75 \pm 17.42(97)$ \\
\hline TRF $^{3}$ &
\end{tabular}

${ }^{1}$ Average of 3 or 4 treatments: $\alpha$-Tocopherol $(1+2+3) ; \alpha$-Tocotrienol $(4+5+6)$; TRF (mixture of $\alpha-, \gamma-, \delta$-tocotrienols; $7+8+9+10$ ). Reported as thousands $/ \mu$ l.

${ }^{2}$ Average of duplicate analyses of 3 or 4 treatments: $\alpha$-Tocopherol $(1-3)$; $\alpha$-Tocotrienol $(4-6)$; TRF $(7-10)$. Reported as thousands $/ \mu$ l.

${ }^{3} \mathrm{TRF}=$ tocotrienol rich fraction ( $\alpha$-tocotrienol $+\gamma$-tocotrienol $+\delta$-tocotrienol)

${ }^{4}$ Percentages of pre-dose or post-dose values are in parentheses.

PRP, pre- and post-treatment platelet counts also did not change significantly with $\alpha$-tocopherol (196.00 \pm 6.93 vs $194.00 \pm 6.00)$, $\alpha$-tocotrienol $(187.67 \pm 10.79$ vs $175.33 \pm 10.79)$, and TRF $(170.00 \pm 24.49$ vs $164.75 \pm$ 17.42) thousand/ $\mu \mathrm{L}$ (Table 1$)$.

\section{Effects of tocols in vivo}

As mentioned above, none of these compounds, when injected intravenously, had any significant effect on hematocrit levels or platelet counts in whole blood or in PRP, though small, non-significant decreases were observed (Table 1), which is characteristic of this model. We utilized the Folts' arterial injury model of stenosis and thrombosis because the effects of various compounds on platelet aggregation and plateletmediated thrombus formation can be determined by measuring the cyclic flow reductions (CRFs) in mechanically stenosed circumflex coronary arteries (MSCCA). The size and frequency of these CFRs is directly related to the level of in vivo platelet aggregation activity $[42,43]$. Specifically, platelet-mediated thrombi form periodically in the stenosed coronary artery. This is followed by distal embolization, which produces cyclic reductions in measured coronary blood flow, known as cyclic flow reductions (CFRs) $[42,43]$. It has also been demonstrated that CFRs in mechanically stenosed canine arteries can be eliminated by platelet inhibitors (e.g. aspirin, prostacyclin, and the nitric oxide donor sodium nitroprusside) $[44,45]$.

In the present study, there were no significant changes in blood pressure or heart rate during, or following, the intravenous (IV) administration of $\alpha$-tocopherol, $\alpha$-tocotrienol, or TRF. Importantly, however, the IV injection of $\alpha$-tocopherol, $\alpha$-tocotrienol or TRF consistently abolished cyclic flow reductions (CFRs) in mechanically stenosed circumflex coronary arteries of dogs. The average mean time between the IV injection of TRF (10 $\mathrm{mg} / \mathrm{kg}$ ) and the abolition of cyclic flow reduction (CFRs) was $68.4 \pm 12 \mathrm{~min}$ (range 22-130 $\mathrm{min}$ ). Once abolished, CFRs did not return to pre-dose values, despite challenge with epinephrine (standard drug for restoring CFRs to normal or pre-dose level) or increases in percent laminal stenosis. Monitoring for the return of CFRs to pre-dose levels was continued for as long as $160 \mathrm{~min}$ (range 50$160 \mathrm{~min}$ ) post abolition of CFRs. Similar results were also obtained with IV of $\alpha$-tocopherol $(20 \mathrm{mg} / \mathrm{kg})$, and $\alpha$ tocotrienol $(10 \mathrm{mg} / \mathrm{kg})$ for CFRs. The average mean time between $\alpha$-tocopherol $(20 \mathrm{mg} / \mathrm{kg}), \alpha$-tocotrienol (10 mg/ $\mathrm{kg})$ or TRF $(10 \mathrm{mg} / \mathrm{kg} ; \alpha-+\gamma-+\delta$-tocotrienols $)$ intravenous administration and blood sample collection for determining platelet aggregation and tocol levels was 88 $\pm 10 \mathrm{~min}$ (41-117 min). The results of these studies support the concept that $\alpha$-tocopherol, $\alpha$-tocotrienol, and TRF all have protective effects against intravenous platelet aggregation and thrombus formation.

\section{Effects of $\alpha$-tocopherol, $\alpha$-tocotrienol or TRF on ex vivo platelet aggregation}

In order to further evaluate the potential protective effects of tocols on platelet aggregation, we tested their effect on ex vivo collagen-induced platelet aggregation in PRP. Our results demonstrated that tocols had profound, and significant, effects on collagen-induced platelet aggregation. Platelet aggregation in PRP 6 minutes after treatment with $\alpha$-tocopherol, $\alpha$-tocotrienol, or TRF (mixture of pure tocotrienols only) was reduced by $22 \%$, $59 \%$ and $92 \%$, respectively $(\boldsymbol{P}<0.001$; Figure 2$)$. TRF 

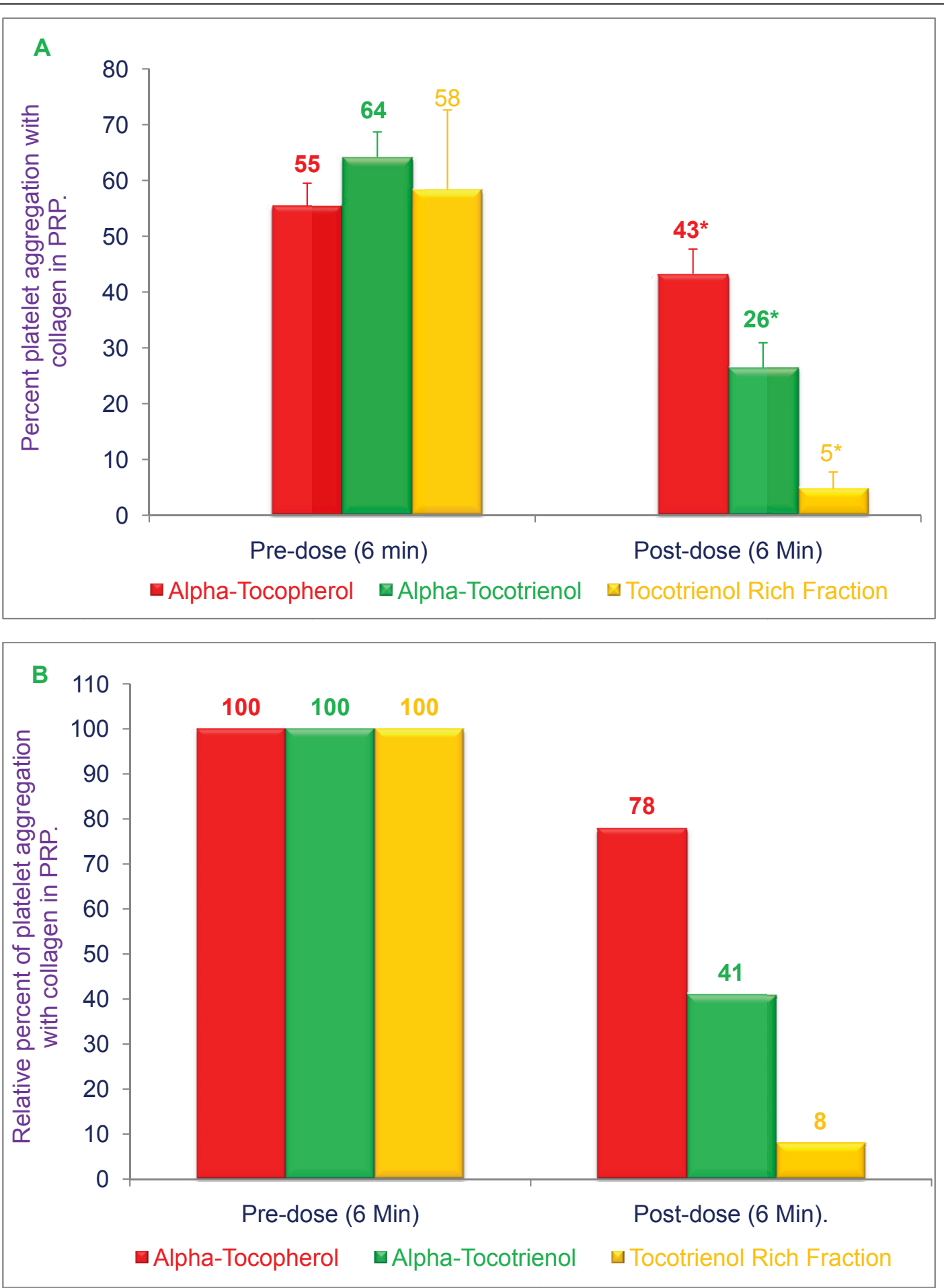

Figure 2 Effects of $\alpha$-tocopherol, $\alpha$-tocotrienol, and tocotrienol rich fraction (TRF) on collagen-induced platelet aggregation: $\alpha$ Tocopherol $(250 \mu \mathrm{g}), \alpha$-tocotrienol $(250 \mu \mathrm{g})$ or TRF $(250 \mu \mathrm{g})$ were dissolved in polyethylene glycol $(1 \mathrm{~mL})$ solvent and stored at $-20^{\circ} \mathrm{C}$. Plasma $(40 \mathrm{~mL})$ was warmed to $50^{\circ} \mathrm{C}(20 \mathrm{~min})$ prior to injection. $\alpha$-Tocopherol, $\alpha$-tocotrienol or TRF solutions in $1 \mathrm{~mL}$ of polyethylene glycol were added to warmed plasma, vortexed vigorously, and then administered over 30 seconds through a femoral arterial line to anesthetized dogs. Collagen $(12.5 \mu \mathrm{mol} / \mathrm{mL})$ in a volume of $32 \mu \mathrm{L}$ was added to $400 \mu \mathrm{L}$ of PRP that had been incubated at $37^{\circ} \mathrm{C}$ for $2 \mathrm{~min}$. The extent of collagen-induced platelet aggregation was quantitated by measuring the percent maximal aggregation 6 min after adding collagen. Data are expressed as means $\pm \mathrm{SD}, n=3$ ( $\alpha$-tocopherol), 3 ( $\alpha$-tocotrienol), and 4 (TRF) dogs respectively, per treatment. Figure 2A is based on raw values and 2B is based on percentages compared to their respective pre-dose and post-dose control values. An asterisk indicates significant differences at $P<0.001$ for each treatment compared to respective controls. 
was the most potent inhibitor amongst these compounds.

Tocols $(\alpha$-tocopherol, $\alpha$-tocotrienol, or tocotrienols $[\alpha-+\gamma-+\delta$-tocotrienol $])$ also significantly inhibited adenosine diphosphate (ADP)-induced platelet aggregation in platelet rich plasma (PRP) as shown in Figure 3. Compared to pre-dose values, the extent to which platelet aggregation was inhibited at 2.5 and $6.0 \mathrm{~min}$ after the addition of ADP was $14 \%$ and $16 \%(\boldsymbol{P}<0.05)$ for $\alpha$ tocopherol, 24\% and 34\% $(\boldsymbol{P}<0.05)$ for $\alpha$-tocotrienol, and $22 \%$ and $42 \%(\boldsymbol{P}<0.025)$ for TRF (Figure 3$)$. The maximal inhibition of platelet aggregation was, again, obtained with TRF (Figure 3).

\section{Effects of $\alpha$-tocopherol, $\alpha$-tocotrienol and TRF on the concentrations of tocols in plasma and platelets of dog}

The concentrations of $\alpha-, \beta, \gamma, \delta$-tocopherols and $\alpha$-, $\beta$-, $\gamma$-, $\delta$-tocotrienols were estimated in plasma and platelets before injection and after CFRs were abolished. Following $\alpha$-tocopherol treatment, tocopherol levels increased from $17.60 \pm 0.32$ to $56.91 \pm 0.18 \mu \mathrm{g} / \mathrm{mL}(\boldsymbol{P}<0.025)$ in pre-dose vs post-dose plasma specimens, respectively, and from $10.05 \pm 0.27$ to $42.22 \pm 0.21 \mu \mathrm{g} / \mathrm{mL}$ in predose vs post-dose platelets, respectively $(\boldsymbol{P}<0.025)$ as shown in Table 2. On the other hand, $\alpha$-tocopherol treatment did not significantly change tocotrienol levels in plasma (2.89 to $1.49 \mu \mathrm{g} / \mathrm{mL})$ or in platelets (2.84 to $2.33 \mu \mathrm{g} / \mathrm{mL}$; Table 2). Following $\alpha$-tocotrienol treatment, tocopherol levels increased from $10.10 \pm 0.82$ to $45.11 \pm$ $2.19 \mu \mathrm{g} / \mathrm{mL}$ in pre-dose vs post-dose plasma specimens, respectively, and from $5.12 \pm 1.24$ to $28.16 \pm 1.54 \mu \mathrm{g} /$ $\mathrm{mL}$ in pre-dose vs post-dose platelets $(\boldsymbol{P}<0.025)$ as shown in Table 3. $\alpha$-Tocotrienol treatment induced relatively modest increases in tocotrienol levels in plasma ( $0.90 \pm 0.03$ to $2.78 \pm 0.13$ ) and in platelets (1.02 \pm 0.03 to $1.28 \pm 0.04$ ) as shown in Table 3. Pre-dose vs. post-dose levels of tocopherols and tocotrienols were also increased significantly with TRF treatment (tocopherols in plasma, $19.72 \pm 1.29$ to $67.38 \pm 2.25 \mu \mathrm{g} / \mathrm{mL}$; tocotrienols in plasma $1.65 \pm 0.03$ to $8.56 \mu \mathrm{g} / \mathrm{mL} \pm 0.04$; tocopherols in platelets, $7.85 \pm 0.62$ to $31.44 \pm 1.84$; tocotrienols in platelets, $3.85 \pm 0.23$ to $3.84 \pm 0.12 \mu \mathrm{g} /$ $\mathrm{mL}$ ) as shown in Table 4.

Although treatment with the various tocols had relatively modest effects on pre-dose vs. post-dose treatment levels of tocotrienols, these same treatments had much more profound effects on tocopherol levels (Tables 3, 4). After $\alpha$-tocopherol treatment, total tocopherol concentrations increased approximately 3 -fold in plasma and 4-fold in platelets (Table 2). Similarly, after treatment with $\alpha$-tocotrienol and TRF, tocopherol levels increased more than a 4-fold and 5-fold, in plasma and platelets, respectively (Tables 3,4 ). It has been demonstrated that administering $\gamma$-tocotrienol or $\mathrm{TRF}_{25}$ capsules to hypercholesterolemic humans for 4-weeks significantly increased serum $\alpha$-tocopherol concentrations compared to baseline values [33,41]. This bioconversion was further confirmed by demonstrating the conversion of $\gamma-\left(4-{ }^{3} \mathrm{H}\right)$ tocotrienol to $\alpha$-tocopherol in vivo using chickens $[35,37,41]$.

\section{Discussion}

Results of the present study clearly demonstrate the inhibitory effect of tocotrienols on in vivo platelet thrombus formation and ex vivo platelet aggregation using the Folt's stenosed canine coronary artery model. Significant and marked inhibition of collagen- or ADPinduced platelet aggregation was observed with $\alpha$-tocotrienol and TRF $(\alpha-,+\gamma-,+\delta$-tocotrienols $)$ treatments. This inhibition exceeded that achieved with $\alpha$-tocopherol under similar conditions (Figs. 2, 3). This is the first report in which the effects of tocotrienols on platelet aggregation in vivo and ex vivo have been evaluated using the Folts' Model [40]. Although $\alpha$-tocopherol, $\alpha$ tocotrienol and TRF treatments were all effective in inhibiting collagen- and ADP-induced platelet aggregation in platelet rich plasma, the inhibition achieved with TRF was significantly greater than that observed with either $\alpha$-tocopherol or $\alpha$-tocotrienol. As mentioned earlier, the TRF used in this study contained $\alpha-, \gamma$ - and $\delta$ tocotrienols $(15 \%, 25 \%$, and $60 \%$, respectively), and was free of $\alpha$-tocopherol.

Treatment with all of the tocols produced significant and pronounced increases in tocopherol concentrations in plasma and platelets. The effect of tocol treatments on tocotrienol levels was much more modest. It is important to recognize that $\alpha$-tocopherol is the major form of vitamin $\mathrm{E}$ in plasma and platelets, even after treatment with pure $\alpha$-tocotrienol or $\mathrm{TRF}_{25}$, due to bioconversion of tocotrienols to $\alpha$-tocopherol [33-39,41]. The conversion of tocotrienols to $\alpha$-tocopherol in plasma or platelets following IV injection in the current study suggests that uptake of tocotrienols by plasma or platelets is relatively rapid in the Folts model. To our knowledge, the time dependency of tocotrienol uptake in plasma or platelets has not been reported, and the results reported herein suggest that the majority of tocotrienols are ultimately converted to tocopherols as reported earlier [35,37,41], although the site of this conversion cannot be determined from the present data. Moreover, it is also unclear if the biological effects described above (i.e. decreased platelet aggregation, abrogation of CRF's) are secondary to tocotrienols, tocopherols, or a combination of both. The magnitude of the increase in plasma or platelet tocopherol concentrations in the present study is greater than that achieved in most dietary supplementation studies using $\alpha$-tocopherol or tocotrienols, and it could be speculated that 

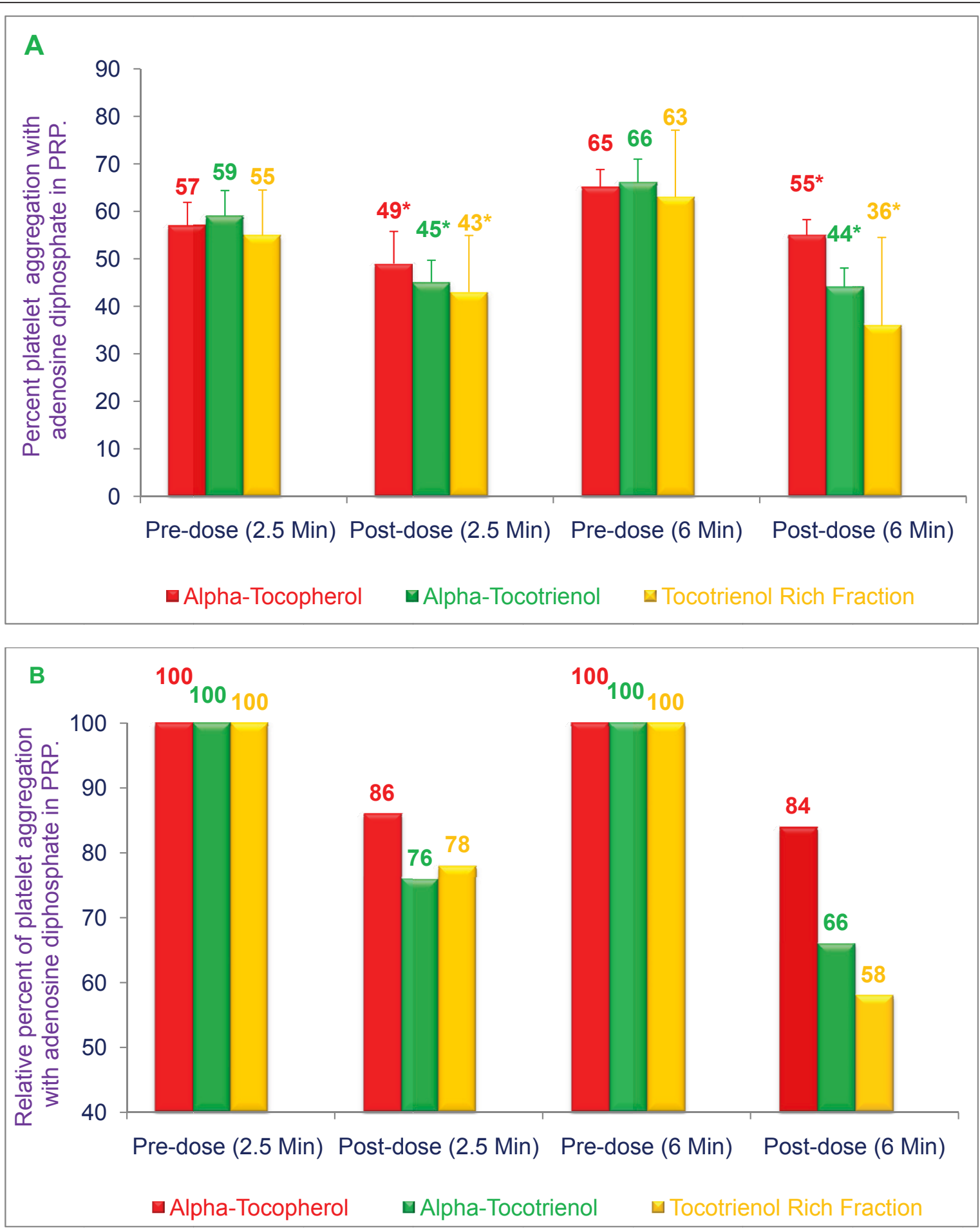

Figure 3 Effects of $\alpha$-tocopherol, $\alpha$-tocotrienol, and tocotrienol rich fraction (TRF) on adenosine diphosphate-induced platelet aggregation: $\alpha$-Tocopherol $(250 \mu \mathrm{g}), \alpha$-tocotrienol $(250 \mu \mathrm{g})$ or TRF $(250 \mu \mathrm{g})$ were dissolved in polyethylene glycol $(1 \mathrm{~mL}$ each) and stored at $-20^{\circ} \mathrm{C}$. Plasma $\left(40 \mathrm{~mL}\right.$ ) was warmed to $50^{\circ} \mathrm{C}(20 \mathrm{~min})$ prior to injection. The $\alpha$-tocopherol, $\alpha$-tocotrienol or TRF solution was added to the warmed plasma and vortexed vigorously, and then administered over 30 seconds through a femoral arterial line of the anesthetized dog. Adenosine diphosphate (ADP; $20 \mu \mathrm{mol} / \mathrm{mL}$ ) in a volume of $32 \mu \mathrm{L}$ was added to $400 \mu \mathrm{L}$ of PRP that had been incubated at $37^{\circ} \mathrm{C}$ for $2 \mathrm{~min}$. The extent of adenosine diphosphate -induced platelet aggregation was quantitated by measuring the percent maximal aggregation at 2.5 min and 6 min after adding ADP. Data are expressed as means \pm SD, $n=3$ ( $\alpha$-tocopherol), 3 ( $\alpha$-tocotrienol), and 4 (TRF) dogs respectively, per treatment. Figure $3 \mathrm{~A}$ is based on raw values and $3 \mathrm{~B}$ based on percentages compared to their respective pre-dose and post-dose control values. An asterisk indicates significant differences at $P<0.05$ for each treatment compared to their respective control values. 
Table 2 Effects of $\alpha$-tocopherol on the concentration of tocols in canine plasma and platelets ${ }^{1}$

\begin{tabular}{|c|c|c|c|}
\hline Treatments & Total tocopherols $(T)^{2}$ & Total tocotrienols $(\mathrm{T} 3)^{3}$ & Total T + T3 \\
\hline$\alpha$-Tocopherol (T) & & entrations in $\mu \mathrm{g} / \mathrm{ml}$ (ppm) & \\
\hline \multicolumn{4}{|l|}{ Plasma (Pre-dose) } \\
\hline Total Tocols ${ }^{4}$ & $17.60 \pm 0.32^{\mathrm{a}}(86)^{5}$ & $2.89 \pm 0.05^{\mathrm{a}}(14)$ & $20.49 \pm 0.26^{\mathrm{a}}(100)$ \\
\hline \multicolumn{4}{|l|}{ Plasma (Post-dose) } \\
\hline Total Tocols & $56.91 \pm 0.18^{\mathrm{b}}(97)$ & $1.49 \pm 0.03^{b}(3)$ & $58.40 \pm 1.65^{\mathrm{b}}(100)$ \\
\hline \multicolumn{4}{|c|}{ Platelets (Pre-dose) } \\
\hline Total Tocols & $10.05 \pm 0.27^{\mathrm{a}}(80)$ & $2.84 \pm 0.02^{\mathrm{a}}(20)$ & $12.89 \pm 0.29^{\mathrm{a}}(100)$ \\
\hline \multicolumn{4}{|c|}{ Platelets (Post-dose) } \\
\hline Total Tocols & $42.22 \pm 0.21^{b}(95)$ & $2.33 \pm 0.04^{\mathrm{a}}(5)$ & $44.55 \pm 0.22^{b}(100)$ \\
\hline
\end{tabular}

${ }^{1}$ Data expressed as means $\pm S D, n=3,3$, and 4 respectively, per treatment.

${ }^{2}$ Total tocopherols $=$ Mixture of $\alpha$-tocopherol $+\beta$-tocopherol $+\gamma$-tocopherol $+\delta$-tocopherol $(\mathrm{T})$.

${ }^{3}$ Total tocotrienols $=$ Mixture of $\alpha$-tocotrienol $+\beta$-tocotrienol $+\gamma$-tocotrienol $+\delta$-tocotrienol (T3).

${ }^{4}$ Tocols $=$ Mixture of $\alpha-, \beta-, \gamma-$, and $\delta$-tocopherols (T) $+\alpha-, \beta-, \gamma-$, and $\delta$-tocotrienols (T3).

${ }^{5}$ Percentages of control values are in parentheses.

${ }^{\text {a-b }}$ Values in columns with a different superscript letter are significantly different at $P<0.05$.

tocotrienols are utilized more efficiently than tocopherols by plasma or platelets. The increase in plasma tocopherols was also greater than that seen in most dietary supplementation studies using various formulations of $\alpha$-tocopherol in $\mathrm{TRF}_{25}$ or Palmvitee capsules $[35,37,41]$. Whether the greater plasma and platelets levels of tocopherols in the present study are the result of a unique effect of tocotrienols, the intravenous route of administration, the formulation used $\left(\mathrm{TRF}_{25}\right.$, Palmvitee), or an effect of improved recovery during assay of these vitamin E compounds, cannot be determined from these data.

Table 3 Effects of $\alpha$-tocotrienol on the concentration of tocols in canine plasma and platelets ${ }^{1}$

\begin{tabular}{lccc}
\hline Treatments & Total tocopherols $(\mathrm{T})^{2}$ & Total tocotrienols $(\mathrm{T} 3)^{3}$ & Total T + T3 \\
\hline$\alpha$-Tocotrienol (T3) & & Concentrations in $\mu \mathrm{g} / \mathrm{ml}(\mathrm{ppm})$ & \\
\hline
\end{tabular}

Plasma (Pre-dose)
Total Tocols ${ }^{4}$
$10.10 \pm 0.82^{\mathrm{a}}(92)^{5}$
$0.90 \pm 0.03^{\mathrm{a}}(8)$
$11.02 \pm 0.81^{\mathrm{a}}(100)$

Plasma (Post-dose)

Total Tocols

$45.11 \pm 2.19^{b}(94)$

$2.78 \pm 0.13^{\mathrm{b}}(6)$

$47.89 \pm 2.17^{\mathrm{b}}(100)$

Platelets (Pre-dose)

Total Tocols

$5.12 \pm 1.24^{\mathrm{a}}(83)$

$1.02 \pm 0.03^{\mathrm{a}}(7)$

$6.14 \pm 1.22^{\mathrm{a}}(100)$

Platelets (Post-dose)

Total Tocols

$28.16 \pm 1.54^{\mathrm{b}}(96)$

$1.28 \pm 0.04^{\mathrm{a}}(4)$

$29.44 \pm 1.52^{\mathrm{b}}(100)$

${ }^{1}$ Data expressed as means $\pm \mathrm{SD}, n=3,3$, and 4 respectively, per treatment.

${ }^{2}$ Total tocopherols $=$ Mixture of $\alpha$-tocopherol $+\beta$-tocopherol $+\gamma$-tocopherol $+\delta$-tocopherol (T).

${ }^{3}$ Total tocotrienols $=$ Mixture of $\alpha$-tocotrienol $+\beta$-tocotrienol $+\gamma$-tocotrienol $+\delta$-tocotrienol (T3).

${ }^{4}$ Tocols $=$ Mixture of $\alpha-, \beta-, \gamma-$, and $\delta$-tocopherols (T) $+\alpha-, \beta-, \gamma-$, and $\delta$-tocotrienols (T3).

${ }^{5}$ Percentages of control values are in parentheses.

${ }^{\mathrm{a}-\mathrm{b}}$ Values in columns with a different superscript letter are significantly different at $P<0.05$. 
Table 4 Effects of TRF on the concentrations of tocols in canine plasma and platelets ${ }^{1}$

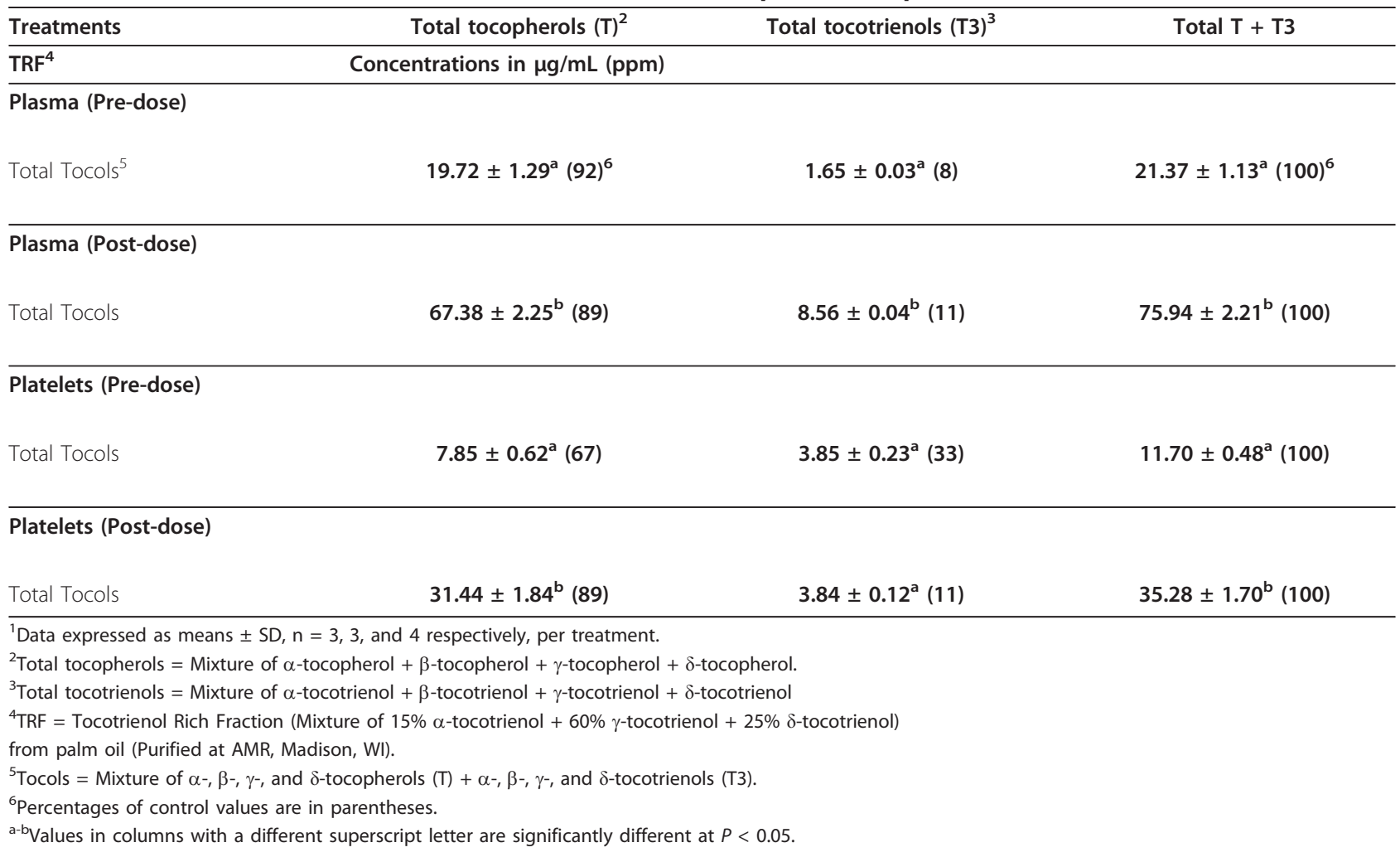

Although, the present study does not delineate the mechanism of action of tocopherols or tocotrienols on platelet function, previous reports have suggested that $\alpha$-tocopherol inhibits platelet thromboxane $\mathrm{A}_{2}$ production, increases vascular $\mathrm{PGI}_{2}$ production, inhibits the platelet release reaction, inhibits platelet calcium mobilization, alters platelet membrane fluidity, and inhibits platelet phospholipase $\mathrm{A}_{2}[46,47]$. It has been also demonstrated that tocotrienols are highly effective at reducing expression of adhesion molecules on endothelial cells and inhibiting monocyte adhesion to endothelial cells [48].

Recently, it was reported that $\alpha$-tocopherol inhibits platelet-mononuclear cell interaction, platelet aggregation and platelet protein kinase activity induced with either phorbol 12-myristate 13-actate or thrombin in humans [49]. Dietary supplementation of $\alpha$-Tocopherol significantly inhibited the superoxide production, lipid oxidation, IL-1 $\beta$ secretion monocyte-endothelial cell due to inhibition of protein kinase activity [50]. In humans, $\alpha$-Tocopherol also partially inhibits platelet protein kinase $C(\mathrm{PKC})$, and this action of $\alpha$-tocopherol on platelet function provides new insights into the anti-thrombotic and atherogenic properties of $\alpha$-tocopherol [51].

Moreover, the mixture of $\alpha-, \gamma-, \delta$-tocopherols were more effective in preventing platelet aggregation as compared to $\alpha$-tocopherol alone observed in humans [52]. This inhibition of platelet aggregation was associated with increased release of nitric oxide due to activation of endothelial constitutive nitric-oxide synthase and protein kinase C [52]. Similarly, the effects of $\alpha$-tocopherol and $\gamma$-tocopherol differ with respect to low-density-lipoprotein oxidation, superoxide activity, platelet aggregation and arterial thrombogenesis in human studies [53]. $\gamma$-Tocopherol is more potent than $\alpha$-tocopherol in these effects also [53]. However, most studies only show an effect in cultured cells or under ex vivo conditions. Importantly, cell culture studies are often conducted under conditions of vitamin $\mathrm{E}$ deficiency. This might partially explain the inconsistency observed between cell culture studies and studies performed in animals or humans [53].

Combined treatment of diabetic rats with $\alpha$-tocopherol and acetylsalicyclic acid (aspirin) had a greater inhibitory effect on platelet aggregation, and reduced nitric oxide production, than either treatment alone $[47,54]$. Combination therapy also improved balance of thromboxane and prostacyclin compared to untreated diabetic rats $[47,54]$. Consequently, this combination therapy appears to induce beneficial physiologic changes that may protect tissues from detrimental thrombotic and ischemic phenomena [54]. It has previously been demonstrated that 
tocopherol levels in platelets are depressed in diabetic subjects and that these low levels may contribute to the increased incidence of atherosclerosis and thrombotic events in diabetic patients [55-57]. Supporting this concept is the demonstration that dietary $\alpha$-tocopherol has been demonstrated to reverse abnormalities of platelet function in diabetic rats and patients [49-52]. The above mentioned properties and other positive biological effects of tocopherols have been reviewed comprehensive by Reiter et al. [58].

Recently, tocotrienols were found to be potent neuroprotective agents against stroke [31,59]. Specifically, incorporation of tocotrienols into the diet of hypertensive rats protected them against stroke-induced injury $[31,59]$. This protective property of tocotrienols was due its inhibition of pp66 (c-Src gene) kinase activation and 12-Lipoxygenase, which protect against glutamase- and stroke-induced neurodegeneration [60]. This protective effect of tocotrienols (in nanomolar concentrations) is independent of their antioxidant activity because tocopherols were effective only at higher (micromolar) concentrations [32]. Recently, it was reported that $\gamma$ tocotrienol was the most cardioprotective of all the isomers, followed by $\alpha$ - and $\delta$-tocotrienols [61]. It was also suggested that, although these isomers possess comparable antioxidant properties, their abilities to potentiate signal transduction could be different [61]. On the other hand, our previous and recent findings showed that tocotrienols exhibit varying degrees of biological activity with $\delta$-tocotrienol showing the most potency, followed by $\gamma$-tocotrienol, and then by $\alpha$-tocotrienol $[23,29]$. The present results show that a mixture of tocotrienols containing mainly $\gamma$-, and $\delta$-tocotrienol, is more potent than $\alpha$-tocotrienol with respect to inhibition of collagen- or ADP-induced platelet aggregation. Further studies are required to clarify the potency of $\gamma$-tocotrienol vs $\delta$ tocotrienol.

\section{Conclusions}

Administration of intravenous tocotrienols markedly inhibits collagen and ADP-induced platelet aggregation, inhibits in vivo platelet thrombosis, and induces a 2-fold and 4-fold increase in plasma and platelet levels of $\alpha$ tocopherol, respectively. These treatments induced less pronounced increases in plasma or platelet tocotrienols levels, suggesting that intravenous administered tocotrienols were ultimately converted to tocopherols in this model, comparable to results obtained in humans, hamsters, guinea pigs and swine [33-39,62-64]. The above results also suggest that tocotrienols and tocopherols may be important physiologically and therapeutically in the prevention of thrombotic events and atherosclerosis, and that tocotrienols can be used to supplement currently used antiplatelet agents. Aspirin and clopidogrel resistance are well-described phenomena [65,66], and the search for more effective anti-platelet agents is ongoing. The enhanced cholesterol-lowering properties of tocotrienols may make these compounds even more attractive than $\alpha$-tocopherol as potential therapeutic or prophylactic agents for platelet inhibition and protection against myocardial infarction and stroke.

\section{Abbreviations}

APTF: Acute Platelet-mediated Thrombus Formation; CFRs: Cyclic Flow Reductions; HPLC: High Pressure Liquid Chromatography; IV: intravenous; MSCCA: Mechanically Stenosed Circumflex Coronary Arteries; PA: Platelet Aggregation; PPP: Platelet Poor Plasma; PRP: Platelet Rich Plasma; T: Tocopherol; T3: Tocotrienol; Tocols: Mixture of $\alpha-, \beta-, \gamma-, \delta$-tocopherols $+\alpha-$, $\beta-, \gamma-, \delta$-tocotrienols; TRF: Tocotrienol rich fraction from palm oil (Mixture of $15 \%$ a-tocotrienol $+60 \% \gamma$-tocotrienol $+25 \% \delta$-tocotrienol); $\operatorname{TRF}_{25}$ :

Tocotrienol rich fraction of rice bran (a-tocopherol 8.7\%, a-tocotrienol 15.5\%, $\beta$-tocotrienol 1.6\%, $\gamma$-totrienol 39.4\%, $\delta$-tocopherol 4.4\%, $\delta$-tocotrienol 5.2\%, $d$-desmethyl tocotrienol $20.9 \%$, unidentified tocotrienols $4.3 \%$ ).

\section{Acknowledgements}

We thank Ms. Lei He of Department of Nutrition Sciences, University of Wisconsin, Madison for helpful discussions and technical assistance for carrying out the estimation of tocols (tocopherols and tocotrienols) by HPLC of all dog's samples (plasma and platelets) at Advanced Medical Research, 8251 Raymond Road, Madison, Wisconsin, 53719, USA. We also thank Mr. Keith Gilchrist (USDA, ARS, MWA, Cereals and Crops Research Laboratory, Madison, WI, 53726, USA) for carrying out statistical analyses of the data. The TRF (mixture of $\alpha$-tocopherol $+\alpha-, \gamma$-, $\delta$-tocotrienols) of palm oil was supplied by Malaysian Palm Oil Board, Kuala Lumpur, Malaysia (previously known as Palm Oil Research Institute of Malaysia [PORIM]). This study was supported in part by Advanced Medical Research (AMR) and NIH grant GM50870 (NQ). The study was carried out under a FDA approved IND number 36906 .

\section{Author details}

'Department of Basic Medical Science, School of Medicine, 2411 Holmes Street, University of Missouri, Kansas City. MO 64108, USA. ${ }^{2}$ Advanced Medical Research, 8251 Raymond Road, Madison, Wisconsin, 53719, USA. ${ }^{3}$ Prairie Cardiovascular Consultants, 619 East Mason Street, Suite 4P57, Springfield, IL 62701, USA. ${ }^{4}$ Department of Pharmacology/Toxicology, 2464 Charlotte Street, University of Missouri, Kansas City, MO 64108, USA. ${ }^{5}$ Department of Medicine, Cardiovascular Medicine Section, 2537 Chamberlain Av. Room A, Madison Wisconsin, 53705, USA.

\section{Competing interests}

The authors declare that they have no competing interests. Authors' contributions

All the authors were involved in the design of the study. CWK carried out studies in vivo using dogs, and also performed ex vivo platelets aggregation studies using dog's samples in the laboratory of JDF. JDF is the pioneer in developing cyclic flow reductions (CFRs) model. CJP edited the manuscript. All the authors have read and approved the final version.

Received: 23 February 2011 Accepted: 14 April 2011

Published: 14 April 2011

\section{References}

1. Krauss RM, Deckelbaum RJ, Ernst N, Fisher E, Howard BV, Knopp RH, Kotchen T, Lichtenstein AH, McGill HC, Pearson TA, Prewitt TE, Stone NJ, Horn LV, Weinberg R: Dietary guidelines for healthy American adults: A statement for physicians and health professionals by the Nutrition Committee. American Heart Association. Circulation 1996, 94(7):1795-1800.

2. U.S Department of Agriculture. U.S. Department of Health and Human Services: Nutrition and Your Health. In Dietary Guidelines for Americans. Volume 232.. 4 edition. Washington, DC: U.S. Printing Office, Home and Garden Bulletin No; 1995. 
3. Witztum JL, Steinberg D: Role of oxidized low density lipoprotein in atherogenesis. J Clin Invest 1991, 88:1785-1792.

4. Parthasarathy $S$, Renkin SM: Role of oxidized low density lipoprotein in atherogenesis. Prog Lipid Res 1992, 92:127-143.

5. Berliner JA, Heinecke JW: The role of oxidized lipoproteins in atherogenesis. Free Radical Biol Med 1996, 20:707-727.

6. Steinberg D, Parthasarathy S, Carew TE: Beyond cholesterol: modification of low density lipoprotein that increase its atherogenicity. N Engl J Med 1989, 320:915-924.

7. Clark MW: Vitamin E in human health and disease. Clin Laboratory Sciences 2008, 45(5):417-430.

8. Traber MG: Vitamin E decrease heart attack risk? Summary and implications with respect to dietary recommendations. J Nutr 2001, 131:395S-397S

9. Yusuf S: Vitamin E supplementation and cardiovascular events in highrisk patients. N Engl J Med 2000, 342(3):154-160.

10. Upston JM, Terentis AC, Stocker R: Tocopherol-mediated peroxidation of lipoproteins: Implication for vitamin $\mathrm{E}$ as potential antiatherogenic supplement. FASEB J 1999, 13:977-994.

11. Deveraj S, Adams-Huet B, Fuller CJ, Jialal I: Dose-response comparison of RRR-a-tocopherol and all-racemic a-tocopherol on LDL oxidation. Arterio Throm Vasc Biol 1997, 17:2273-2279.

12. The heart outcome prevention evaluation study investigators: Vitamin $E$ supplementation and cardiovascular events in high-risk patients. N Engl $J$ Med 2000, 342(154-160).

13. Miller ER III, Pastor-Barriuso R, Dalal D, reimersma RA, Appel LJ, Guallar E: Meta analysis: High dose of vitamin E supplementation may increase allcause mortality. Ann Intern Med 2005, 142:947-951.

14. Richardson PD, Steiner M: Adhesion of human platelets inhibited by vitamin E. In Vitamin E in health and disease. Edited by: Packer L, Fuchs J. Mercel Decker: New York; 1993:297-311.

15. Vericel E, Croset M, Sedivy P: Platelets and aging: Aggregation, arachidonate metabolism and antioxidant status. Thrombosis Res 1988, 49:331-342.

16. Jandak J, Steiner M, Richardson PD: Reduction of platelet adhesiveness by vitamin E supplementation in humans. Thrombosis Res 1988, 49:393-404.

17. Szczeklik A, Gryglewski RJ, Domagala B: Dietary supplementation with vitamin $E$ in hyperlipoproteinemias: Effects on plasma lipid peroxide, antioxidant activity, prostacyclin generation \& platelet aggregability. Thromb Haemostas 1985, 54:425-430.

18. Steiner M: Effect of alpha-tocopherol administration on platelet function in man. Thromb Haemostas 1983, 49:636-640.

19. Yoshida $Y$, Saito $Y$, Jones $L S$, Shigeri $Y$ : Chemical reactivities and physical effects In comparison between tocopherols and tocotrienols: Physiological significance and prospects as antioxidant. J biosci \& Bioeng 2007, 104(6):439-445

20. Rasool AHG, Yuen KH, Yusoff K, Wong AR, Rahman ARA: Dose-dependent elevation of plasma tocotrienols levels and its effect on arterial compliance, plasma total antioxidant status, and lipid profile in healthy humans supplemented with tocotrienol rich vitamin E. J Nutr Sci Vitaminol 2006, 52:473-478

21. Yoshida Y, Niki E, Noguchi N: Comparative study on the action of tocopherols and tocotrienols as antioxidant: Chemical and physical effects. Chem Phys Lipids 2003, 123:63-75.

22. Packer $L$, Weber SU, Rimbach $G$ : Molecular aspects of a-tocotrienol antioxidant action and cell signaling. J Nutr 2001, 131:369S-373S

23. Qureshi AA, Mo H, Packer L, Peterson DM: Isolation and structural identification of Novel tocotrienols from rice bran with hypocholesterolemic, antioxidant and antitumor properties. J Agr Food Chem 2000, 48:3130-3140.

24. Kamal-Eldin A, Appelqvist LA: The chemistry and antioxidant properties of tocopherols and tocotrienols. Lipids 1996, 31:671-701.

25. Suarna C, Hood RL, Dean RT, Stocker R: Comparative antioxidant activity of tocotrienols and other natural lipid-soluble antioxidants in a homogeneous system in rat and human lipoproteins. Biochem Biophys Acta 1993, 1166:163-170.

26. Serbinova E, Kagan V, Han D, Packer L: Free radical recycling and intramembrane mobility in the antioxidant properties of alphatocopherol and alpha-tocotrienol. Free Radic Biol Med 1991, 10:263-275.

27. Yamaoka M, Carrillo MJH: Effects of tocopherols \& tocotrienols on the physicochemical property of the liposomal membrane in relation to their antioxidant activity. Chem Phys Lipids 1990, 55:295-300.
28. Komiyama K, lizuka K, Yamaoka M, Watanabe H, Tsuchiya N, Umezawa L: Studies on the biological activity of tocotrienols. Chem Pharm Bull 1989, 37:1369-1371.

29. Qureshi AA, Reis JC, Papasian CJ, Morrison DC, Qureshi N: Tocotrienols inhibit the lipopolysaccharides-induced pro-inflammatory cytokines in murine macrophages and female mice. Lipids in Health and Disease 2010 9:143.

30. Sen CK, Khanna S, Roy S: Tocotrienols in health and disease: The other half of the natural vitamin E family. Molecular Aspects of Medicine 2007, 28:692-728.

31. Khanna S, Roy S, Parinandi NL, Maurer M, Sen CK: Charcterization of potent neuroprotective properties of the natural vitamin E a-tocotrienol. J Neurochemistry 2006, 98:1474-1486.

32. Das S, Powell SR, Wang P, Divald A, Nesaretam K, Tosaki A, Cordis GA, Maulik N, Das DK: Cardioprotection with palm oil tocotrienols: Antioxidant activity of tocotrienol is linked with its ability to stabilize proteasome. Am J Physiol Heart Circ Physiol 2005, 289:H361-H367.

33. Qureshi AA, Sami SA, Salser WA, Khan FA: Dose-dependent suppression of serum cholesterol by tocotrienol-rich fraction $\left(\mathrm{TRF}_{25}\right)$ of rice bran in hypercholesterolemic humans. Atherosclerosis 2002, 161:199-207.

34. Qureshi AA, Salser AW, Parmer R, Emeson EE: Novel tocotrienols of rice bran inhibit Atherosclerotic lesions in C57BL/6 apo-deficient mice. J Nutr 2001, 131:2606-2618

35. Khor HT, Ng TT: Effects of administration of a-tocopherol and tocotrienols on serum lipids and liver HMG-CoA reductase activity. PORIM International PalmOil Congress (PIPOC), Nutrition Conference 1999, 1-6, Febuary:177-186.

36. Qureshi AA, Bradlow BA, Salser WA, Brace LD: Novel tocotrienols of rice bran modulate cardiovascular diseases risk parameters of hypercholesterolemic humans. J Nutr Biochem 1997, 8:290-298.

37. Atroshi F, Antila E, Sankari S, Treuthardt J, Gapor A: Palm oil vitamin E effects in hypercholesterolemia, lipid soluble antioxidant. In Biochemistry and Clinical Applications. Edited by: Ong ASH, Packer L. Birkhauser Verlag, Basel/Switzerland; 1995:575-581

38. Qureshi AA, Bradlow BA, Brace L, Manganello J, Peterson DM, Pearce BC, Wright JJK, Gapor A, Elson CE: Response of hypercholesterolemic subjects to administration of tocotrienols. Lipids 1995, 30:1171-1177.

39. Qureshi N, Qureshi AA: Tocotrienols, novel hypocholesterolemic agents with antioxidant Properties. In Vitamin E in Health and Disease. Edited by: Packer L, Fuchs J. Mercel Dekker, Inc., New York, NY; 1993:247-267.

40. Folts JD: An in vivo model of experimental arterial stenosis intimal damage, and periodic thrombosis. Circulation 1991, 83IV:IV3-IV14

41. Qureshi AA, Sami SA, Salser WA, Khan FA: Synergistic effect of tocotrienol rich fraction $\left(\mathrm{TRF}_{25}\right)$ of rice bran and lovastatin on lipid parameters hypercholesterolemic humans. J Nutr Biochem 2001, 12:318-329.

42. Bush $L R$, Shebuski RJ: In vivo models of arterial thrombosis and thrombolysis. FASEB J 1990, 4:3087-3088.

43. Demrow HS, Peter BS, Slane R, Folts JD: Administration of wine and grape juice Inhibits in vivo platelet activity and thrombosis in stenosed canine arteries. Circulation 1995, 91:1182-1188.

44. Sébastien P, Sakariassen KS, Turitto VT, Baumgarner HR: Effects of aspirin and epinephrine on experimentally induced thrombogenesis in dogs: A parallelism between in vivo and ex vivo thrombosis model. Arteriosclerosis and Thrombosis 11:1182-1191, 119

45. Rovin JD, Stamler JS, Loscalzo J, Folts JD: Sodium nitroprusside, an EDRF cogener, Increases platelet cyclic GPP levels and inhibits epinephrineexacerbated in vivo Platelet thrombus formation in stenosed canine coronary arteries. J Cardiovasc Pharmacol 1993, 22:626-631.

46. Chan AC, Wagner M, Kennedy C, Chen E, Lanuville O, Mezi VA, Tran K Choy PC: Vitamin $E$ up-regulates arachidonic acid release and phospholipase $\mathrm{A}_{2}$ in mega-karyocytes. Mol Cell Biochem 1998 189:153-159.

47. Karpen CW, Pritchard KAJr, Arnold JH, Cornwell DG, Panganamala RV: Restoration of prostacyclin/thromboxane balance in the diabetic rat. Influence of dietary vitamin E. Diabetes 1982, 31:947-951.

48. Theriault A, Chao JT, Gapor A: Tocotrienol is the most effective vitamin E for reducing endothelial expression of adhesion molecules and adhesion to monocytes. Atherosclerosis 2002, 160:21-30.

49. Murohara T, Ikeda H, Otsuka Y, Aoki M, Haramaki N, Katoh A, Takajo Y, Imaizumi T: Inhibition of platelet adherence to mononuclear cells by atocopherol. Circulation 2004, 110:141-148. 
50. Devaraj S, Li D, Jialal I: The effects of alpha tocopherol supplementation on monocyte function. Decreased lipid oxidation, interleukin 1 beta secretion on monocyte function and monocyte adhesion to endothelium. J clin Investig 1996, 98:756-763.

51. Freedman JE, Farhat JH, Loscalzo J, Keany JFJ: a-Tocopherol inhibits aggregation of human platelets by a protein kinase C-dependent mechanism. Circulation 1996, 94:2434-2440.

52. Liu M, Wallmon A, Olsson-Mortlock C, Wallin R, Saldeen T: Mixed tocopherols inhibit platelet aggregation in humans: potential mechanisms. Am J Clin Nutr 2003, 77:700-706.

53. Saldeen T, Li D, Mehta JL: Differential effects of alpa- and gammatocopherol on low-density lipoprotein oxidation, superoxide activity, platelet aggregation and arterial thrombogenesis. J Am Coll Cardiol 1999, 34(4):1208-1215.

54. Gonzàlez-Correa JA, Arrebola MM, Guerrero A, Cañda J, Muñoz-Marín J, Sánchez de la Cuesta F, De la Cruz JP: Antioxidant and anti-platelet effects of alpha-tocopherol-aspirin combination in type 1-like diabetic rats. Life Sciences 2006, 79:1405-1412.

55. Karpen CW, Cataland S, O'Dorisio TM, Panganamala RV: Interrelation of platelets vitamin $\mathrm{E}$ and thromboxane synthesis in type I diabetese mellitus. Diabetes 1984, 33:239-243.

56. Karpen CW, Cataland S, O'Dorisio TM, Panganamala RV: Production of 12hydroxy-eicosatetraenoic acid and vitamin E status in platelet from type I human diabetic subjects. Diabetes 1985, 34:526-531.

57. Colette C, Pares-Herbute N, Monnier LH, Carty E: Platelet function in type I diabetes: Effects of supplementation with large doses of vitamin E. Am J Clin Nutr 1988, 47:256-261.

58. Reiter $E$, Jiang $Q$, Christen $S$ : Anti-inflammatory properties of $a$ - and $Y$ tocopherol. Molecular Aspects of Medicine 2007, 28:668-691.

59. Khanna S, Roy S, Slivka A, Craft TK, Chaki S, Rink C, Notestine MA, DeVries AC, Parinandi NL, Sen CK: Neuroprotective properties of the natural vitamin E alpha-tocotrienol. Stroke 2005, 36:2258-2264.

60. Sen CK, Khanna S, Roy S, Packer L: Molecular basis of vitamin E action. Tocotrienol potently inhibits glutamate-induced pp60 (c-Src) kinase activation and death of HT4 neural cells. J Biol Chem 2000, 275:13049-13055.

61. Das S, Lekli I, Das M, Szabo G, Varadi J, Juhasz B, Bak I, Nesaretam K, Tosaki A, Powell SR, Das DK: Cardioprotection with palm oil tocotrienols: Comparison of different isomers. Am J Physiol Heart Circ Physiol 2008, 294: H970-H978.

62. Choudhury N, Tan L, Truswell AS: Comparison of palmolein and olive oil: Effects on plasma lipids and vitamin $\mathrm{E}$ in young adults. Am J Clin Nutr 1995, 61:1043-1051.

63. Qureshi AA, Peterson DM, Hasler-Rapacz JO, Rapacz J: Novel tocotrienols of rice bran suppress cholesterogenesis in hereditary hypercholesterolemic swine. J Nutr 2001, 131:223-230.

64. Qureshi AA, Qureshi N, Hasler-Rapacz JO, Weber FE, Chaudhary V, Crenshaw TD, Gapor A, Chong YH, Ong ASH, Peterson DM, Rapacz J: Dietary tocotrienols reduce concentrations of plasma cholesterol, apolipoprotein B, thromboxane B2 and platelet factor 4 in pigs with inherited hyperlipidemias. Am J Clin Nutr 1991, 53:1042S-1046S.

65. Gum PA, Kottke-Merchant K, Welsh PA, White J, Topol EJ: A prospective, blinded determination of the natural history of aspirin resistance among stable patients with cardiovascular disease. J Am Coll Cardiol 2003, 41:961-965.

66. Wiviot SD, Antman EM: Clopidogrel resistance. A new chapter in a fast moving story. Circulation 2004, 109:3064-3067.

do: 10.1186/1476-511X-10-58

Cite this article as: Qureshi et al:: Tocotrienols-induced inhibition of platelet thrombus formation and platelet aggregation in stenosed canine coronary arteries. Lipids in Health and Disease 2011 10:58.

\section{Submit your next manuscript to BioMed Central and take full advantage of:}

- Convenient online submission

- Thorough peer review

- No space constraints or color figure charges

- Immediate publication on acceptance

- Inclusion in PubMed, CAS, Scopus and Google Scholar

- Research which is freely available for redistribution

Submit your manuscript at www.biomedcentral.com/submit
Biomed Central 